\title{
Seasonal variation in the prevalence of larvae of Aedes aegypti mosquito in district Hyderabad, Sindh, Pakistan
}

\author{
Mukhtiar Ahmed Channa*and Nasreen Memon \\ Department of Zoology, University of Sindh, Jamshoro-Pakistan \\ *Corresponding author's email: mukhtiarchanna75@gmail.com \\ Citation \\ Mukhtiar Ahmed Channa and Nasreen Memon. Seasonal variation in the prevalence of larvae of Aedes aegypti \\ mosquito in district Hyderabad, Sindh, Pakistan. Pure and Applied Biology.Vol. 9, Issue 2, pp1354-1363. \\ http://dx.doi.org/10.19045/bspab.2020.90142
}

Received: 22/11/2019 Revised: 21/01/202

Accepted: 04/02/2020

Online First: 24/02/2020

\section{Abstract}

Entomological surveillance for the prevalence and seasonal variations of Aedes aegypti (Dengue and Chikungunya vector) mosquito larvae was conducted during July 2016 to June 2017 in district Hyderabad. In the role of being Aedes aegypti as potential vector of Dengue \& Chikungunya, arboviral infections commonly prevalent in Lower Sindh. The outcome of study was designed on predictive modeling exercise so that rapid response in terms of larvicidal activity either biological method or mechanical or growth regulation could be implemented at positive localities besides identifying prospective geographical distribution in order to assess future interventions well in time prior to peak season. At onset of surveillance, larvae were collected from various types of indoor and outdoor water holding containers/breeding habitat. underground tanks, overhead tanks, plastic drums, earthen pots, discarded receptacles, plant nurseries, puncture tire shops and road side small hotels (Dhaba). A standard method was used for data collection and analysis (house index HI, container index CI and Breteau index BI). A total of 510 household surveyed with 1370 water holding containers in which 372 were positive with Aedes aegypti larvae at the rate of $27.1 \%$; while 344 outdoor water containers examined, 46 were positive with Aedes aegypti larvae at the rate of 13.37\%. Total of 1714 indoor and outdoor water holding containers examined, 418 were positive with Aedes aegypti larvae with overall positivity rate of $24.38 \%$. For entomological indices only indoor water containers data have been used. House Index (HI), Container Index (CI) and Breteau Index (BI) were estimated as 31\%, $27.1 \%$ and $73 \%$ respectively. Drums were recorded with highest positivity rate of $(40.17 \%)$, followed by underground water tanks $(29.07 \%)$, overhead water tanks $(22.8 \%)$, Earthen pot $(22.6 \%)$, discarded containers $(12.1 \%)$ and the least $(10.7 \%)$ dripping water collection from air-condition and refrigerator. From outdoor breeding-sites, Plant nurseries were recorded highest $17.1 \%$ followed by Dhaba hotel $(15.5 \%)$ and puncture tire shops (10.6\%). The seasonal variations were noted as September and October were observed the peak seasons with positivity rate of $51.25 \%$ and $58.27 \%$ respectively and the reason is that the favorable climatic factors after monsoon; $131.8 \mathrm{~mm}$ rain fall in August 2016 and the favorable temperature and relative humidity as well for the breeding of Aedes aegypti. Positive water containers were distinguished with ratio as properly covered, partially covered and uncovered $1.91 \%, 49.76 \%$ and $48.3 \%$ respectively.

Keywords: Aedes aegypti larvae; Breeding-sites; Dengue/Chikungunya Vector; Hyderabad; Larval indices; Prevalence; Seasonal variation 


\section{Introduction}

Mosquitoes are very small flying insects of order Diptera, they cause public health problem by their blood sucking habit. Female mosquitoes bite and suck human blood to strengthen their eggs production, their painful bite not only cause itching and discomfort but transmit many protozoal and viral diseases like Malaria, Dengue, Chikungunya, Yellow fever, ZIKA, West Nile virus, Elephantiasis etc. in human and animals as well.

A massive population of mosquitoes can crop up under favorable environmental conditions with available water to breed in. Aedes aegypti breed in fresh water man made water containers available in or around the houses, female bites in day time [1].

Among insect transmitted diseases, more than 700 million people are annually affected by mosquitoes alone [2]. The major mosquito borne diseases in Pakistan including Sindh province are Malaria and Dengue. Recently in December 2016, first time in the history of Pakistan an outbreak of Chikungunya virus hit the various areas of Karachi city and after few months from April 2017 onward in Tharparkar district of Sindh [3]; Therefore the adjoining districts especially Hyderabad is at high risk of Chikungunya virus because of the presence of vector (Aedes aegypti) [4]. Aedes aegypti most likely originated in Africa; since then, the mosquito has been transported globally throughout the tropical, subtropical, and parts of the temperate world, through global trade and shipping activities [5]. Aedes aegypti mosquitoes have a high vectoral capacity (effectiveness of virus transmission in nature) for DENV (Dengue virus), CHIKV (Chikungunya virus), ZIKV (Zika virus), and YFV (Yellow fever virus).

As there is no any proper medicine for Arboviral diseases (Dengue, Chikungunya etc), therefore the only method of controlling or preventing the viral transmission is to fight against vector (mosquito).All mosquitoes have similar life cycle that breed in standing water, they pass through four distinct life stages: egg, larva, pupa and adult; first three are aquatic while only adult is aerial / terrestrial. The mosquito control in water (aquatic stages/immature stages) is easy and cost effective and fewer efforts required as compared to adult level, because after emerging from pupa, adult mosquito population fly to different directions to rest in dark and shady places, even they prefer to rest under curtains, furniture and cracks inside the rooms.

Larval surveillance is an essential component of an effective mosquito surveillance and control program to identify the key breeding areas and knowledge about the local vector habitat profiles, population dynamics, distribution trend and relative abundance etc for the control of Aedes species [6-8].

In Sindh province only few researchers have worked on prevalence of Aedes aegypti [916] but their work was either confined to Karachi only, except Ansari and Memon (2013) did some work from Hyderabad [4]. Therefore the objectives of present study was to do a thorough work on the prevalence of Aedes aegypti in relation to impact of climatic conditions its population and to explore various indoor and outdoor preferred breeding-sites/ hotspots of Aedes aegypti, their larval abundance, prevalence and seasonal variations for better management of vector mosquitoes in Hyderabad district especially in Hyderabad City which is second largest and thickly populated city of Sindh province at high risk of Dengue, Chikungunya, yellow-fever and ZIKA virus as well.

\section{Materials and methods Study area}

Hyderabad district is subdivided into four taluka namely Hyderabad City, Hyderabad Rural, Latifabad and Qasimabad (Fig. 1). Except Hyderabad rural, rests of the three taluka are urban; Hyderabad city is the 
second largest city of Sindh province. Hyderabad district population 6,234,309 with an area $319 \mathrm{~km}^{2}$, the density is 20,000 people per $\mathrm{km}^{2}$. District located at $25^{\circ} .22^{\prime} 45^{\prime \prime} \mathrm{N}$ latitude and $68^{\circ} .22^{\prime} 06^{\prime \prime} \mathrm{E}$ longitude. The climate of district is most varied. The lowest temperature ever recorded $1 \mathrm{C}^{0}$ on $8^{\text {th }}$ February 2012 and highest temperature ever recorded $50 \mathrm{C}^{0}$ in May 2018.

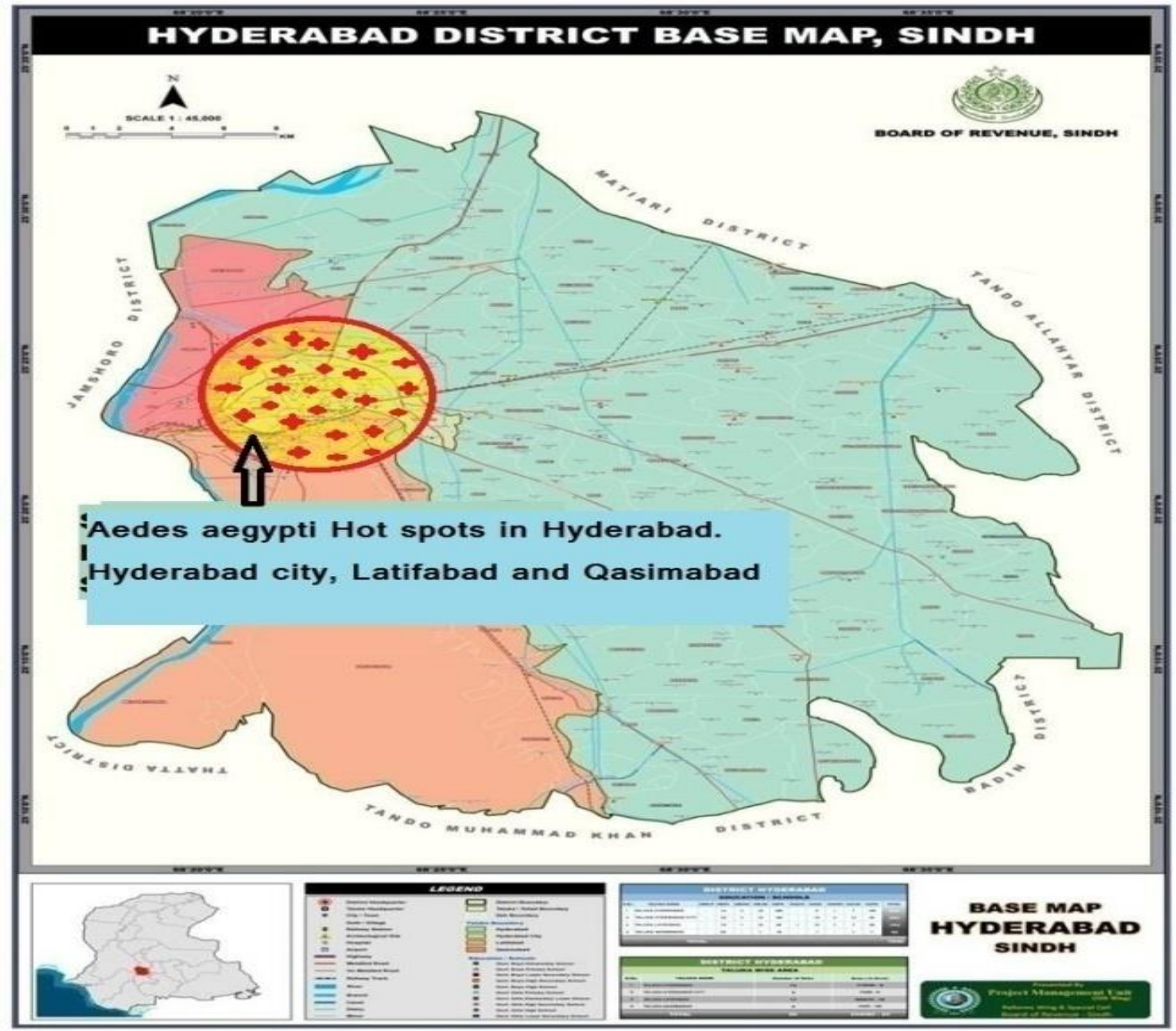

Figure 1. Map of district Hyderabad, Sindh (Study area)

\section{Entomological indices}

House was the basic sampling unit for entomological indices. Door to door visits were conducted; Houses and peri-domestic areas were systematically searched for water holding containers and presence of Aedes aegypti larvae inside these containers if any. The most used indicators for Aedes species surveillance are House Index, (HI; percentage of houses with at least one positive container); Container Index, (CI; percentage of all water-holding containers infested with larvae or pupae and Breteau Index, (BI; number of positive containers per 100 houses inspected [17, 18].

\section{Sample collection}

The collections were made by using various standard equipments as per need and size of 
the water holding container i-e 0.5 liter standard plastic larval dipper, ladle scoop, larval netting with long iron handle of mesh size $(55 \mu \mathrm{m})$, tea strainer, small plastic droppers $3 \mathrm{ml}$ in size and glass dropper 100 $\mathrm{ml}$ size (Fig. 2). Led zooming torch were used in addition to illuminate the water container so that larvae can be clearly seen and collected. Field collections (specimens/larvae) were put into 1 liter plastic bottles; a separate bottle was used for each type of container, properly labeled and brought to the laboratory / fixed station. The key characters (generic and species level) were either examined by magnifying glass or stereo and compound microscope. Identifications were made with the help of available taxonomic keys [19]. The collected larvae were killed by placing them in $60{ }^{\circ} \mathrm{C}$ warm water and thereafter they were removed from water and kept in airtight specimen tubes/bottles containing $70 \%$ alcohol and labeled as per standard procedure. Date of collection, name of locality, type of breeding-site, name of genus/species and number of larvae etc.
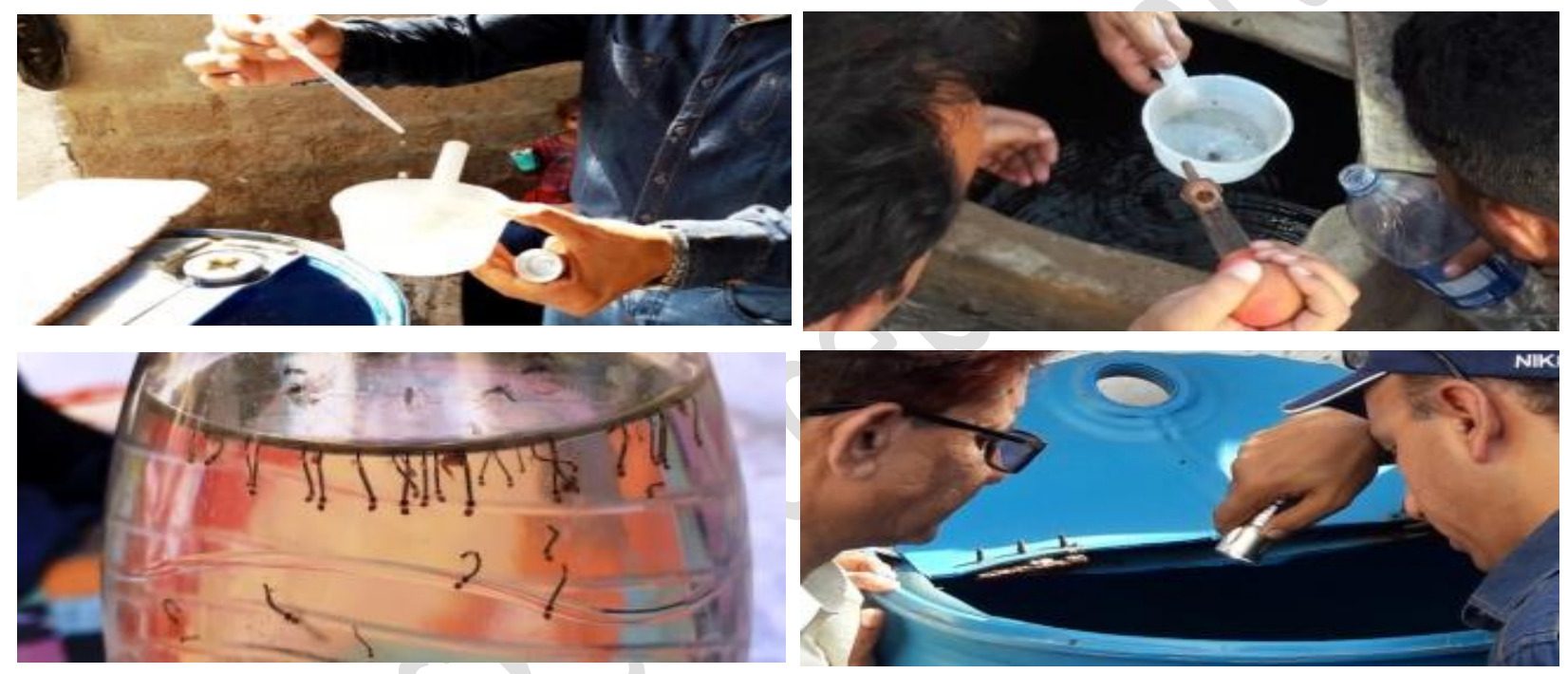

Figure 2. (a, b, c \& d) Collection of Aedes aegypti mosquito larvae from different water holding containers with larval dipper and plastic/glass dropper

\section{Results and discussion}

The Aedes aegypti is called container mosquito, it prefer to breed in small and fresh water indoor and outdoor water containers very close to human habitation.

Indoor breeding-sites further classified into Underground water tanks, Overhead water tanks, Earthen pot (Dila, Matka, Nadi), Drums, Air-conditioner and refrigerator's collected water and discarded containers/ Birds drinking water pots; while outdoor breeding-sites were water containers at Tire puncture shops, Dhaba Hotels and plant nurseries. Only indoor water container survey has been used for entomological indices; total 1370 indoor water containers were inspected in which 372 found positive with Aedes aegypti larvae. The indices were estimated as: House Index (HI) 31\%, Container Index (CI) $27.1 \%$ and Breteau Index (BI) $73 \%$. The average numbers of containers per house were calculated as 2.6. (Table 1).

The presence of Aedes aegypti larvae in household water holding containers were individually calculated. The Drums were recorded with highest positivity rate of $(40.17 \%)$, followed by underground water 
tanks (29.07\%), overhead water tanks $(22.8 \%)$, earthen pot $(22.6 \%)$, discarded containers $(12.1 \%)$ and the least $(10.7 \%)$ from air-condition and refrigerator dripped/collected water (Table 2).

Table 1. Number of household surveyed, House Index, Container Index and Breteau Index with Aedes aegypti larvae in Hyderabad

\begin{tabular}{|c|c|c|c|c|c|c|c|}
\hline \multicolumn{3}{|c|}{ HOUSE INDEX (HI) } & \multicolumn{4}{|c|}{ CONTAINER INDEX (CI) } & \multirow[b]{2}{*}{ BRETEAU (BI) } \\
\hline 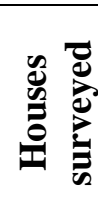 & 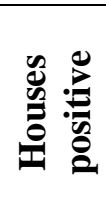 & 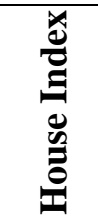 & 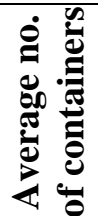 & 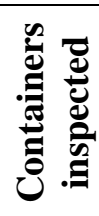 & 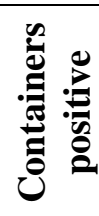 & 这 & \\
\hline 510 & 158 & $31 \%$ & 2.6 & 1370 & 372 & 27.1 & $73 \%$ \\
\hline
\end{tabular}

Table 2. Positivity rate of indoor water containers with Aedes aegypti larvae in Hyderabad

\begin{tabular}{|c|c|c|c|c|c|c|c|c|c|c|c|c|c|c|c|c|c|c|c|c|}
\hline \multicolumn{3}{|c|}{ 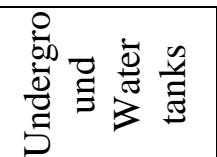 } & \multicolumn{3}{|c|}{ 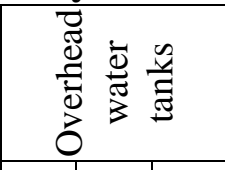 } & \multicolumn{3}{|c|}{ 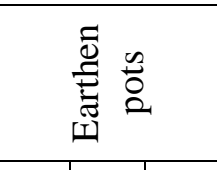 } & \multicolumn{3}{|c|}{ 气 } & \multicolumn{5}{|c|}{ 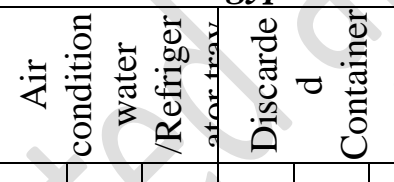 } & & \multicolumn{3}{|c|}{ 崖 } \\
\hline$\stackrel{\frac{\pi}{0}}{\circ}$ & $\stackrel{8}{+}$ & $0^{\circ}$ & $\stackrel{\bar{\Xi}}{0}$ & $\stackrel{0}{+}$ & $\theta^{\circ}$ & 吾 & $\stackrel{0}{+}$ & $b^{\circ}$ & $\begin{array}{c}\frac{\pi}{0} \\
\ominus \\
\ominus\end{array}$ & $\stackrel{0}{+}$ & bo & $\begin{array}{l}\bar{\pi} \\
0 \\
0\end{array}$ & ج & $0^{\circ}$ & $\stackrel{\overrightarrow{\tilde{J}}}{0}$ & $\stackrel{0}{+}$ & $b^{\circ}$ & 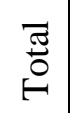 & $\stackrel{0}{+}$ & $0^{\circ}$ \\
\hline 冓 & $\hat{0}$ & aे. & స్ & $\approx$ & $\begin{array}{l}\infty \\
\dot{d}\end{array}$ & ন্ড & $i n$ & $\begin{array}{l}0 \\
\text { ì }\end{array}$ & $\overrightarrow{\mathrm{m}}$ & $\hat{n}$ & o & $\cong$ & $\simeq$ & $\stackrel{\overbrace{}}{\varrho}$ & $\stackrel{\text { ¿ }}{ }$ & 8 & $\overline{\mathrm{I}}$ & $\underset{\substack{2 \\
m}}{2}$ & $\stackrel{N}{n}$ & $\vec{\Delta}$ \\
\hline
\end{tabular}

Aedes aegypti larvae were collected from peri-domestic outdoor premesis from puncture tire shops, dhaba hotels and plant nurseries.Each puncture tire shop has a water tub or small cemented tank filled with water to check the puncture. These water holding tubs/tanks make ideal breeding-sites for Aedes aegypti mosquito; 13 water holding containers/tubs out of 122 with the rate of 10.6\% were positive with Aedes aegypti larvae. Dhaba hotels also store water in plastic drums and clay pots commonly called Nadi and Matka, either uncovered or partially covered containers may support the female Aedes aegypti to lay their eggs in. 29 out of 187 containers with the rate of $15.5 \%$ at dhaba hotels were positive with Aedes aegypti larvae. Most of the plant nursaries have a medium sized cemented tanks approx. $8 \times 8$ feet filled with fresh water. 6 water tanks out of 35 were positivewith the rate of $17.1 \%$. Over all 344 outdoor water containers examined, 46 were positive with the rate of $13.37 \%$. (Table 3).

Total 1714 indoor and outdoor water containers were inspected, 418 were positive with Aedes aegypti larvae at the rate of 24.38 $\%$. (Table 4, Fig. 3 \& 4).

The water holding containers searched/examined for the presence of Aedes aegypti larvae was either properly covered, partially covered or uncovered. Their covering association was compared with positivity; only positive containers were compared. Out of 418 positive containers only $1.91 \%(\mathrm{n}=8)$ were properly covered, whereas $49.76 \% \quad(\mathrm{n}=208)$ were partially covered and $48.3 \%(n=202)$ were uncovered at the time of container examination and sample collection (Table 5 \& Fig. 5). 
Table 3. Positivity rate of outdoor water containers with Aedes aegypti larvae in Hyderabad

\begin{tabular}{|c|c|c|c|c|c|c|c|c|c|c|c|}
\hline \multicolumn{3}{|c|}{$\begin{array}{l}\text { Water tanks/ tubs at } \\
\text { puncture tire shops }\end{array}$} & \multicolumn{3}{|c|}{$\begin{array}{c}\text { Water drums / Earthen } \\
\text { pot (Nadi) at Dhaba } \\
\text { hotel }\end{array}$} & \multicolumn{3}{|c|}{$\begin{array}{c}\text { Cemented water } \\
\text { tanks at plant } \\
\text { nurseries }\end{array}$} & \multicolumn{3}{|c|}{ TOTAL } \\
\hline$\stackrel{\bar{\sigma}}{0}$ & $\stackrel{9}{+}$ & $b^{\circ}$ & $\stackrel{\bar{\Xi}}{0}$ & $\stackrel{+}{+}$ & $0^{\circ}$ & 吾 & $\ddot{+}$ & $b^{\circ}$ & हूँ & $\ddot{z}$ & 8 \\
\hline$\Xi$ & $\simeq$ & $\begin{array}{l}\ddot{8} \\
\ddot{8}\end{array}$ & $\stackrel{\infty}{=}$ & $\stackrel{i}{i}$ & $\stackrel{\hat{\sigma}}{\dot{\jmath}}$ & m & $\stackrel{8}{ }$ & $\vec{\square}$ & 芯 & $\stackrel{+}{+}$ & ڤ్ \\
\hline
\end{tabular}

Table 4. Over all positivity rate of both indoor and outdoor water containers with Aedes aegypti larvae in Hyderabad

\begin{tabular}{|c|c|c|}
\hline Containers examined & Containers positive with Aedes aegypti larvae & Percentage \% \\
\hline 1714 & 418 & 24.38 \\
\hline
\end{tabular}

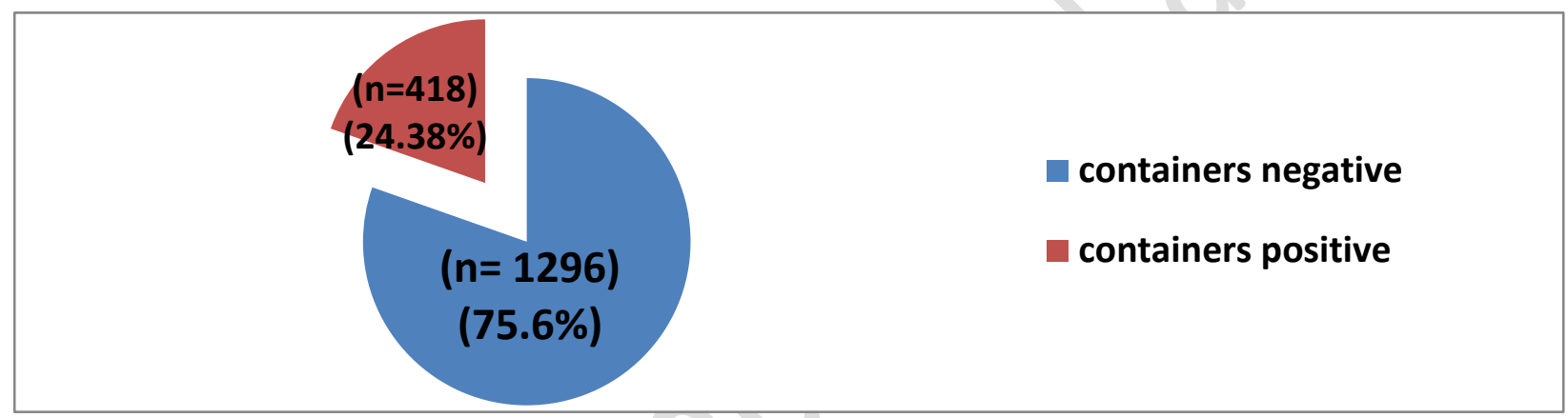

Figure 3.Over all positivity rate of both indoor and outdoor water containers with Aedes aegypti larvae in Hyderabad
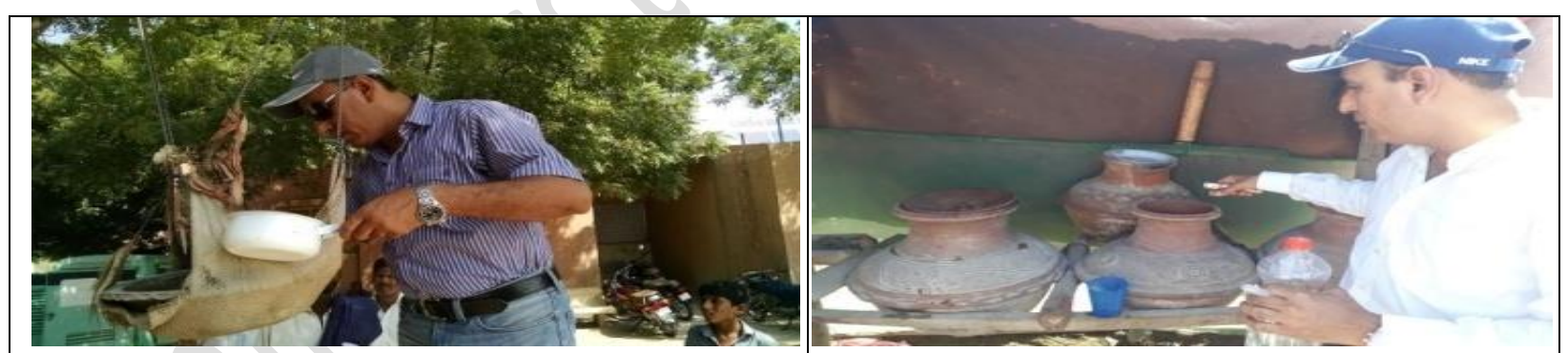

Figure 4a. Household indoor water container Figure 4b. Household indoor water container
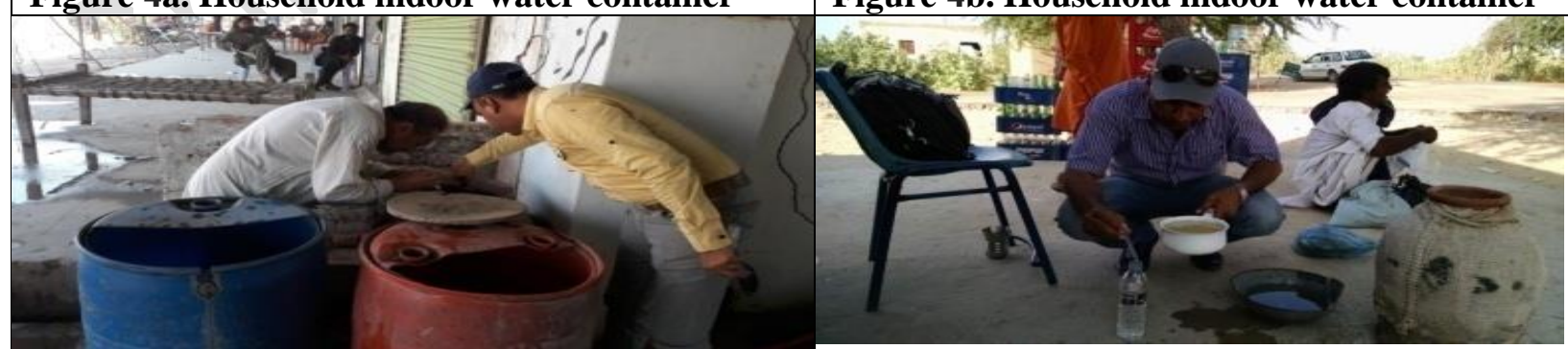

Figure 4c. Outdoor water container at dhaba

Figure 4d. Outdoor water container at kriana hotel shop

Figure 4. Indoor and outdoor water-holding containers and their physical conditions (covered/uncovered) 
Table 5. Association of proper, partially and uncovered containers with positivity rate of Aedes aegypti larvae in Hyderabad

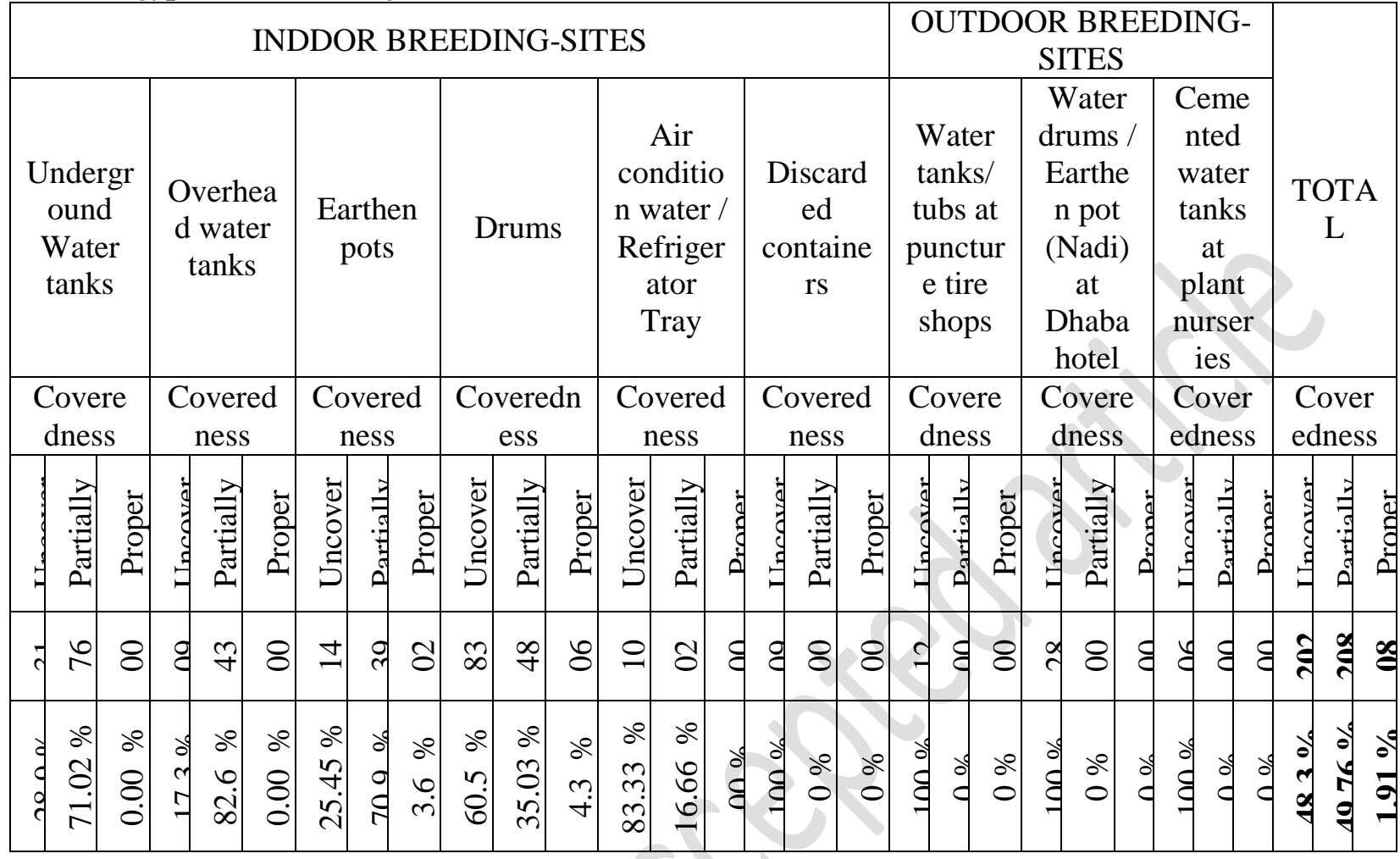

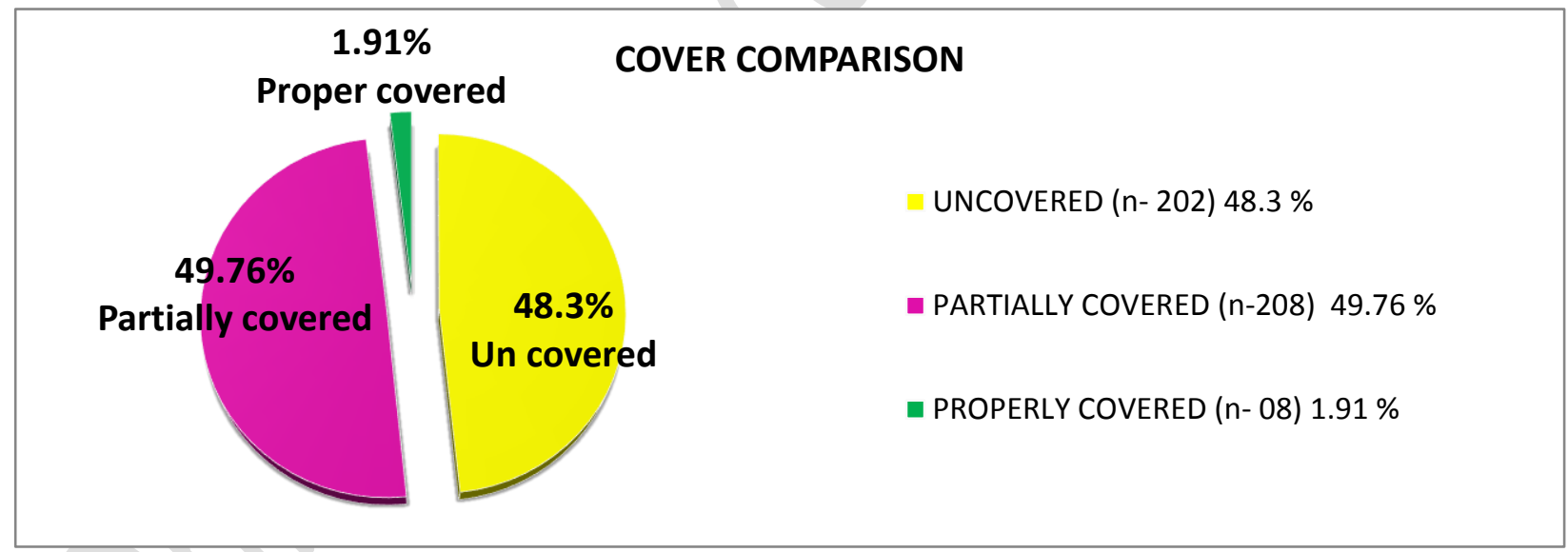

Figure 5. Association of proper, partially and uncovered containers with positivity rate of Aedes aegypti larvae in Hyderabad

The seasonal variations of Aedes aegypti population due to variable climatic factors monitored from July 2016 to June 2017. The September, October and November were observed the peak months with positivity rate of $51.25 \%, 58.27 \%$ and $47.58 \%$ respectively, the reason is $131.6 \mathrm{~mm}$ rainfall in August 2016 in Hyderabad; while January and June were with least positivity rate of $7.46 \%$ and $8.45 \%$ respectively because of cool and hot temperature in these months.

It is observed that climatic factors influence and decreases the population and density of mosquitoes, either temperature is cool or hot in months of January and June respectively; the result show that temperature increases 
from month of April to June as 40.3, 42.0 and $39.2 \mathrm{C}^{0}$ respectively which depressed the mosquito population in other hand temperature starts decreasing from November to January as $17.0,14.5$ and 11.0 $\mathrm{C}^{0}$ respectively and the cooler temperature also effect the mosquito population which can be shown in (Table $6 \&$ Fig. 6). whereas the post monsoon season from September to November remain favorable for various mosquito species including Aedes aegypti (the vector of dengue, Chikungunya, Yellow fever and ZIKA viruses) and mostly month of October identifies as peak month in which mosquito density reaches up to high level from mosquito population and density point of view.

This study recommends that household water containers should be well covered; Solid waste management department must dump out the waste/garbage on daily basis so that no artificial or discarded containers collect the water in monsoon season to make ideal breeding-sites for Aedes aegypti.

Table 6. Month-wise data of seasonal variations of Aedes aegypti population in Hyderabad from July-2016 to June 2017

\begin{tabular}{|c|c|c|c|c|c|c|c|}
\hline Period & \multicolumn{3}{|c|}{ Aedes aegypti Population } & \multicolumn{4}{c|}{ Climatic Factors } \\
\hline Month & $\begin{array}{c}\text { Containers } \\
\text { examined }\end{array}$ & $\begin{array}{c}\text { Containers } \\
\text { positive }\end{array}$ & Percentage & $\begin{array}{c}\text { Temp. } \\
\text { Min. C }\end{array}$ & $\begin{array}{c}\text { Temp. } \\
\text { Max. C }\end{array}$ & $\begin{array}{c}\text { R. H } \\
\text { \% }\end{array}$ & $\begin{array}{c}\text { Rainfall } \\
\text { Mm }\end{array}$ \\
\hline July-2016 & 146 & 14 & $9.58 \%$ & 27.0 & 37.0 & $68 \%$ & NIL \\
\hline August & 135 & 30 & $22.22 \%$ & 25.5 & 35.7 & 64 & $131.8 \mathrm{~mm}$ \\
\hline September & 160 & 82 & $\mathbf{5 1 . 2 5} \%$ & 24.0 & 36.5 & 67 & NIL \\
\hline October & 139 & 81 & $\mathbf{5 8 . 2 7} \%$ & 22.0 & 36.6 & 63 & NIL \\
\hline November & 145 & 69 & $\mathbf{4 7 . 5 8} \%$ & 17.0 & 32.5 & 50 & NIL \\
\hline December & 140 & 26 & $18.57 \%$ & 14.5 & 29.0 & 57 & NIL \\
\hline $\begin{array}{c}\text { January- } \\
\text { 2017 }\end{array}$ & 134 & 10 & $\mathbf{7 . 4 6} \%$ & $\mathbf{1 1 . 0}$ & $\mathbf{2 2 . 0}$ & $\mathbf{5 8}$ & NIL \\
\hline February & 142 & 21 & $14.78 \%$ & 14.4 & 28.6 & 52 & $0.4 \mathrm{~mm}$ \\
\hline March & 126 & 28 & $22.22 \%$ & 18.1 & 34.4 & 43 & NIL \\
\hline April & 138 & 24 & $17.39 \%$ & 23.0 & 40.3 & 44 & NIL \\
\hline May & 147 & 21 & $14.28 \%$ & 25.1 & 42.0 & 54 & NIL \\
\hline June & 142 & 12 & $08.45 \%$ & 27.6 & 39.2 & 62 & $14.0 \mathrm{~mm}$ \\
\hline Total & 1714 & 418 & \multicolumn{3}{|l}{} & & \\
\hline
\end{tabular}

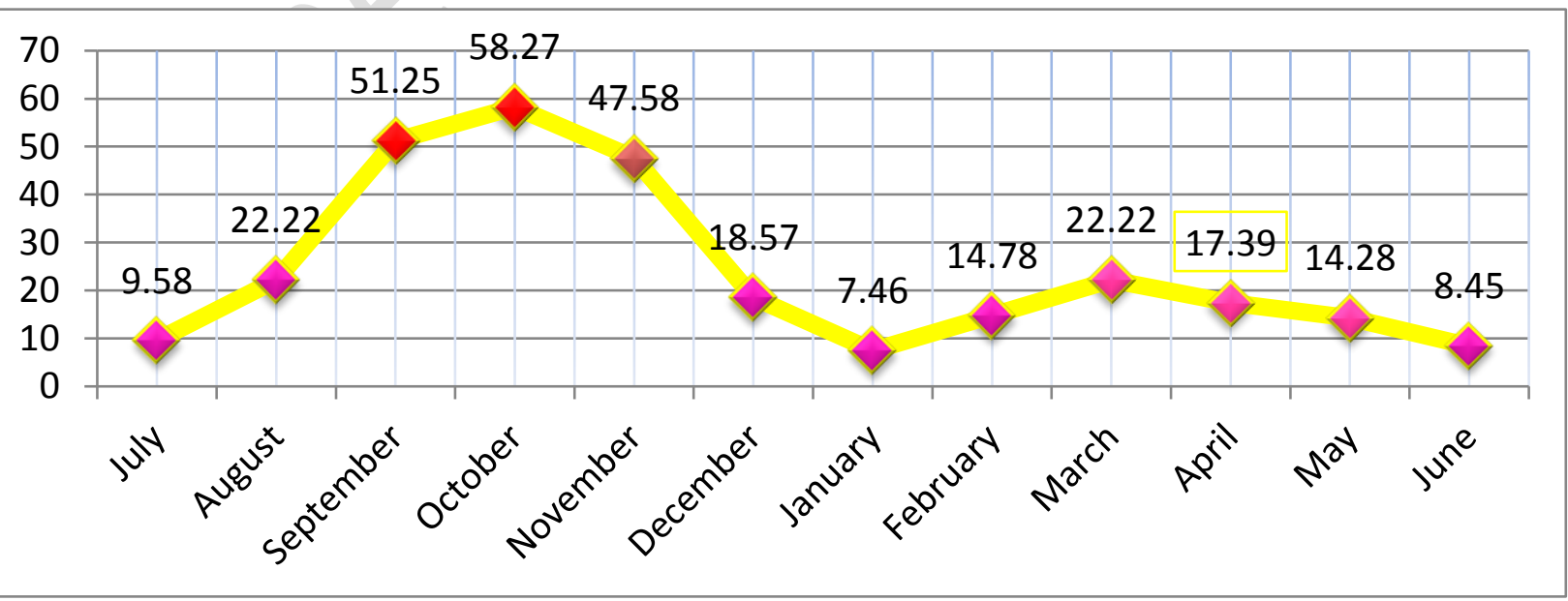

Figure 6. Month-wise data of seasonal variations of Aedes aegypti population in Hyderabad 


\section{Conclusion}

In Sindh province most of the burden of Dengue cases was in Karachi after that in Hyderabad. In 2013 including Karachi, Dengue outbreak hit the various urban areas of Hyderabad district but nobody has ever conducted such type of survey for Aedes aegypti (Dengue vector) in the history of Hyderabad. This survey identified the Aedes aegypti positive localities, their hot-spots, types of breeding-sites and seasonal variations of vector mosquito including peak months. Aedes aegypti is restricted to urban areas of Hyderabad district (Hyderabad city, Latifabad and Qasimabad), the unavailability and shortage of water supply was the one reason of storage water in containers, the improper and/or uncovered containers and post-monsoon favorable climatic factors support Aedes aegypti female to enhance their population. This study will provide the proper guidelines to Dengue control and prevention program Sindh to make a comprehensive strategic plan for better management and control of vector and vector borne diseases are in better interest of public of Hyderabad.

\section{Authors' contributions}

Conceived and designed the experiments: $\mathrm{N}$ Memon \& MA Channa, Performed the experiments: MA Channa, Analyzed the data: N Memon, MA Channa, Contributed reagents/materials/analysis tools: Entomological laboratory, department of zoology, University of Sindh, Jamshoro \& MA Channa, Wrote the paper: MA Channa.

\section{References}

1. Suleman M \& Shafqat K (1993). Notes on Aedine mosquitoes as Diurnal Pests of Human skin Abbottabad Area. Pak $J O$ Zool 25(3): 253-260.

2. Aregawi M, Cibulskis $\mathrm{R}$, Otten $\mathrm{M}$, Williams R, Dye C (2008). World malaria report. Geneva: World Health Organization (WHO). 190.
3. PDSRU (Provincial Disease Surveillance and Response Unit) report (2017), Director General Health Services Sindh. (Unpublished).

4. Ansari A \& Memon NS (2013). Ecology of Aedes aegypti and incidence of Dengue cases in Hyderabad, Sindh, Pakistan. (Unpublished, M.Phil Thesis).

5. Powell JR \& Tabachnick WJ (2013). History of domestication and spread of Aedes aegypti - a review. Memórias do Instituto Oswaldo Cruz Suppl 1: 11-17.

6. Chen CD, Nazni WA, Lee HL, Seleena B, Mohd SM, Chiang YF \& Sofian-Azirun M (2006). Mixed breeding of Aedes aegypti (L.) and Aedes albopictus Skuse in four Dengue endemic areas in Kuala Lumpur and Selangor, Malaysia. Trop Biomed 23(2): 224-227.

7. Lagrotta MT, Silva WC \& Souza Santos R (2008). Identification of key areas for Aedes aegypti control through geo processing in Nova Iguaçu, Rio de Janeiro State, Brazil. Cad Saude Publica 24(1): 70-80.

8. Khan I, Farid A \& Alamzeb. (2011). Development of larval diet for Anopheles stephensi mosquitoes in sterile insect program. Annual Report, Nuclear Institute for Food and Agriculture Peshawar Pakistan 41-43.

9. Ahmad I, Tariq RM \& Qadri SS (2009). Scouting and survey of towns of Karachi city for the presence of Dengue vector mosquitoes, Aedes aegypti L. Pak J Entomol Karachi 24 (1 and 2): 61-62.

10. Tariq RM \& Zafar SMN (2000). Why the population of Dengue vector mosquitoes is increasing day-by-day in Karachi and other areas of Sindh, Pakistan. Pak J Entomol Karachi 15 (1 \& 2): 7-12.

11. Tariq RM (2001). Where the mosquitoes Aedes, Anopheles and Culex are breeding in Karachi, Sindh, Pakistan. Pak J Entomol Karachi 16(1\&2): 15-18. 
12. Tariq RM, Ahmad I \& Qadri SS (2010). Population dynamics and mechanical control of Dengue vector mosquito Aedes aegypti and Aedes uniliniatus in seven towns of Karachi. Pak J Entomol Karachi 25(1): 21-26.

13. Tariq RM, Ahmad I, Qadri SS \& Hussain $S$ (2011). Population and prevalence of Dengue vector mosquitoes during winter to summer season with special reference to temperature in Karachi, Sindh Pakistan. Pak J Entomol Karachi 26(1): 77-80.

14. Mukhtar M, Tahir Z, Baloch TM, Mansoor F \& Kamran J (2006-2010) Entomological investigations of Dengue vectors in epidemic-prone districts of Pakistan. Dengue Bulletin 35: 99-115.

15. Kamimura K, Takasu T, Ahmad A \& Ahmad A (1986). A survey of mosquitoes in Karachi area. Pak J Med Assoc 36: 182-187.

16. Naqvi SNH (1992). Survey and Determination of Resistance in Mosquitoes and Houseflies of Karachi Region. PSF-Project No S-KU/Bio 161: 1-132.

17. Connor ME \& Monroe WM (1923). Stegomyia indices and their value in Yellow fever control. Amer J Trop Med \& Hygiene 3: 9-19.

18. World Health Organization (2009). Dengue guidelines for diagnosis, treatment, prevention and control: new edition. Geneva: World Health Organization.

19. Rueda LM (2004). Pictorial keys for the identification of mosquitoes (Diptera: Culicidae) associated with Dengue virus transmission. Zootaxa 589: 160. 